\title{
ARTIGO
}

d० 10.22481/praxisedu.v15i33.5299

\section{CONTRIBUIÇÕES DO (RE)DESENHO DE TAREFAS PARA APROXIMAÇÃO DA MATEMÁTICA COM O ENTORNO SOCIAL DA ESCOLA}

\author{
CONTRIBUTIONS OF THE (RE)DESIGN OF TASKS FOR THE APPROXIMATION OF \\ MATHEMATICS WITH THE SCHOOL'S SOCIAL ENVIRONMENT
}

CONTRIBUCIONES DEL (RE)DISEÑO DE TAREAS PARA APROXIMACIÓN DE LAS MATEMÁTICAS CON EL ENTORNO SOCIAL DE LA ESCUELA

\author{
Jorge Ramos de Sousa \\ Universidade Estadual do Sudoeste da Bahia - Brasil
}

Vicenç Font Moll

Universidade de Barcelona - Espanha

Tânia Cristina Rocha Silva Gusmão

Universidade Estadual do Sudoeste da Bahia - Brasil

Nilson Antonio Ferreira Roseira

Universidade Federal do Recôncavo da Bahia - Brasil

\begin{abstract}
Resumo: Este artigo tem como objetivo identificar as contribuições que o redesenho de tarefas, focadas em situações extramatemáticas, pode trazer para a aproximação da Matemática com outras áreas do conhecimento e ao entorno social de uma escola. A intervenção se deu por meio de encontros formativos com três professores de Matemática dos Anos Finais do Ensino Fundamental com a finalidade de discutir a temática do desenho de tarefas, levando em conta contextos intra e extramatemáticos. Durante os encontros formativos, foi realizado o redesenho de sequências de tarefas que compunham um projeto escolar, tendo como balizadores os Critérios de Idoneidade Didática do Enfoque Ontosemiótico (EOS). Conclui-se que os professores demonstram uma ligeira melhora de seus conhecimentos didáticos, como por exemplo, quando redesenham tarefas abertas e contextualizadas, o mesmo não acontecendo no conhecimento matemático, pois apresentam fragilidades, tanto no domínio de alguns conceitos, como nos processos de formalização matemática.
\end{abstract}

Palavras chave: Conhecimento didático-matemático. Contextos extramatemáticos. (Re)desenho de tarefas.

Abstract: This article is part of a research that synthesize one stage of an intervention in the field of task (re)designing, in which three middle school Mathematics teachers participated. The intervention took place through training meetings to discuss the issue of task design, considering intra and extra mathematical contexts, can bring to the approximation of mathematics with other areas of knowledge 
and to the social environment of a school. During the training meetings, the redesign of task sequences that comprised a school project was carried out, using the Didactic Suitability Criteria of the Ontosemiotic Approach (OSA). As a conclusion, we see that the teachers show a slight improvement in their didactic knowledge, for example, when they redesign open and contextualized tasks, but this improvement does not happen in mathematical knowledge, since they present difficulties in the mastery of some concepts and in the formalization of mathematics.

Keywords: Didactic-mathematical knowledge. Extra mathematical contexts. (Re) design of tasks.

Resumen: Este artículo tiene como objetivo identificar las contribuciones que el rediseño de tareas, focalizadas en situaciones extramatemáticas, puede hacer para aproximar las matemáticas con otras áreas de conocimiento y con el entorno social de la escuela. La intervención se realizó mediante encuentros formativos con tres profesores de matemática de los años finales de la Enseñanza Básica, con la finalidad de discutir sobre la temática del diseño de tareas, teniendo en cuenta contextos intra y extramatemáticos. Durante los encuentros formativos, se realizó un rediseño de una secuencia de tareas, de un proyecto escolar, tomando como pauta para organizar la reflexión los Criterios de Idoneidad Didáctica del Enfoque Ontosemiótico (EOS). Se concluye que los profesores mostraron una ligera mejora de sus conocimientos didácticos, como, por ejemplo, cuando rediseñan tareas abiertas y contextualizadas; pero lo mismo no sucedió con los conocimientos matemáticos ya que presentaron debilidades, tanto en el dominio de algunos conceptos como en el proceso de formalización matemática.

Palabras clave: Conocimiento didáctico-matemático. Contextos Extramatemáticos. (Re)diseño de tareas.

\section{Introdução}

O uso de contextos extramatemáticos no ensino de Matemática, assim como outras provocações contemporâneas (uso de novas tecnologias, busca de inovação, transposição de conteúdos etc) tem se tornado um grande desafio para a área em questão. Embora, em discussões mais superficiais se admita que "contextualizar é preciso", quando há um aprofundamento, jogando a discussão para o "como", o "quando", e o "porque", as dificuldades com este tema começam a se mostrar.

Envolto nessa problemática, o trabalho que aqui propomos nasce da observação das dificuldades de professores de matemática de uma escola de Anos Finais do Ensino Fundamental na cidade de Jaguaquara-BA, para trabalharem em projetos escolares, oficinas pedagógicas, eventos educativos e na articulação dos conhecimentos de sua disciplina a outras realidades. Discutir o entorno social da escola, as demandas da sociedade atual (tecnológicas, científicas, econômicas, sociais) ou a cultura local, pareciam ser as senhas para tirar esses professores de sua "zona de conforto", do trato da matemática como uma disciplina isolada, independente, autônoma em relação às outras áreas do conhecimento. Daí surgiam, não uma 
"má vontade" de trabalhar a relação Matemática-mundo, mas as dificuldades relacionadas a essa tarefa.

Uma pesquisa na literatura a esse respeito nos levou a perceber que não se tratava de uma situação isolada, mas bastante comum, onde a Matemática é por vezes encarada como um amontoado de fórmulas, macetes e algoritmos, distante, portanto, de outras discussões que se travam no interior da escola. Neste sentido, pesquisas como as de Fernandes (2014), Vanegas, Gimenez e Font (2014), e Vanegas (2013), observam que, por um lado, há um descuido das escolas em utilizar temáticas relacionadas à contextualização em Matemática, por outro, quando ocorrem, tais considerações têm acarretado melhorias ao ensino dessa disciplina.

Nesse ponto, um questionamento parece ser necessário: por que a dificuldade dos professores em tratar da contextualização em Matemática? Ou ainda: por que, observando no dia a dia da escola, ou conversando informalmente com professores, esse entrave parece ser maior entre os que ensinam a disciplina (sejam formados em Matemática ou não) do que profissionais que atuam em outras áreas? Ao nos depararmos com tal problemática, pensamos que as dificuldades em questão poderiam advir de lacunas no conhecimento matemático (disciplinar), e didático (domínio pedagógico, em particular, saber trabalhar situações externas à matemática). Diante desse quadro, propomos uma intervenção no campo da formação de professores, utilizando tarefas abertas, envoltas em contextos extramatemáticos, aqueles que permitem uma interação da Matemática com outras áreas do conhecimento e com a realidade social do educando (FONT, 2005, 2006; PONTE; QUARESMA, 2012; VANEGAS, 2013).

Visando contribuir para a formação didático-matemática desses professores, que conforme Godino consiste na junção de conhecimentos disciplinares e pedagógicos, incluso com o domínio de contextos extramatemáticos, propomos o desenho/redesenho de tarefas doravante (re)desenho de tarefas que deveriam ultrapassar os problemas e exercícios comuns, aplicados correntemente nas escolas. Assim, baseados em Font (2005), buscamos promover uma formação utilizando tarefas que fossem "situações ricas", ou seja, aquelas permeadas por contextos diversificados, múltiplas possibilidades de resolução, desafios, exploração de conhecimentos. Dessa forma, propomos aos três professores-participantes da pesquisa a reconstrução das atividades de um projeto escolar ${ }^{1}$ aplicado no primeiro semestre de 2016 na escola, intitulado "O homem do campo", a partir do (re)desenho de tarefas.

\footnotetext{
${ }^{1}$ Nesse trabalho, estamos considerando as atividades aplicadas no projeto "O homem do campo" como uma sequência de tarefas nos moldes daquelas descritas por Gusmão (2014). Dessa forma, por uma questão de foco da pesquisa, não abordaremos aqui discussões teóricas sobre os Projetos de Trabalho (HERNANDES;
} 
Para o processo de (re)desenhos, levamos em consideração os Critérios de Idoneidade $^{2}$ Didática (CID), do Enfoque Ontosemiótico do Conhecimento e da Instrução ${ }^{3}$ Matemática (EOS) de Godino (2009, 2017) e colaboradores (GUSMÃO, 2006; POCHULU; FONT; RODRIGUEZ, 2013; BREDA; FONT; LIMA, 2015): Epistêmico - relativo a Matemática institucional; Cognitivo - relativo à aprendizagem dos alunos; Emocional relativo aos afetos; Interacional - referente a relação professor-aluno e aluno-aluno; Mediacional - relativo aos recursos e tempo e; Ecológico - relacionado a escola/sociedade.

Dentre esses critérios, o ecológico é o que mais se aproxima do nosso objeto de interesse, qual seja: trabalhar contextos na aula de Matemática. Assim, é usando da idoneidade ecológica ${ }^{4}$ que se intenciona o trabalho de estabelecer a "ponte" entre o que se ensina de números, fórmulas e formas e as necessidades dos alunos nas suas relações sociais, profissionais, culturais etc. Dessa forma, nos deparamos com a temática dos contextos intra, e principalmente extramatemáticos, visando que estes permitam enriquecer o conhecimento didático-matemático de professores por meio de tarefas.

Este artigo está inserido em um contexto mais geral de uma pesquisa de mestrado que busca relacionar o (re)desenho de tarefas matemáticas contextualizadas e o desenvolvimento do conhecimento do professor. Assim, na presente produção, discorremos sobre o (re)desenho de uma sequência de tarefas já trabalhada pelos professores-participantes no contexto de um projeto escolar, com o objetivo de: identificar as contribuições que o (re)redesenho de tarefas, focadas em situações extramatemáticas e balizadas segundo os Critérios de Idoneidade Didática, pode trazer para a aproximação da Matemática com outras áreas do conhecimento e ao entorno social da escola.

Este artigo dispõe de alguns tópicos para uma melhor organização. Assim, em seguida apresentamos uma discussão teórica, onde ponderamos sobre temas como os CID, as tarefas matemáticas e os contextos intra e extramatemáticos. A seguir, traçamos um pequeno mapa do caminho metodológico seguido; apresentamos no tópico seguinte a análise de alguns dados

VENTURA, 1998), uma vez que, preferimos centralizar nossas atividades nas tarefas, tratando a questão do projeto de forma mais genérica, como um "projeto escolar".

${ }^{2}$ Esse termo aparece em Godino $(2002,2017)$ como sinônimo de busca de qualidade, adequação e melhoria nos processos de ensino/aprendizagem. Portanto, uma prática idônea é aquela que atingiu bons níveis de qualidade e refletiu no processo de crescimento do professor.

${ }^{3}$ Em Godino $(2011,2017)$ e na didática da matemática de origem espanhola como um todo, a palavra instrução tem significado de processo de ensino e aprendizagem, portanto, vai além do significado corrente aqui no Brasil, de transmissão de conhecimentos.

${ }^{4}$ Dentro do EOS, a noção de "ecologia”, por seguinte, idoneidade ecológica tem uma conotação de relação entre o ambiente escolar, o ambiente externo a ela, e o currículo, que regula essa relação. Embora não tenha se atido à um conceito do ecológico na sua obra, Godino $(2002,2017)$ deixa claro que, escola, currículo e sociedade, são os fatores que entram em jogo quando se fala em "ecologia" dentro do enfoque que propõe. 
que julgamos pertinentes ao objetivo de investigação para, em seguida, tecer algumas conclusões a respeito dos resultados do trabalho realizado.

\section{Os Critérios de Idoneidade Didática}

As sequências de tarefas que aparecerão neste estudo foram (re)desenhadas tendo como suporte teórico os CID (GODINO, 2011), utilizados para balizar a atividade matemática e (re)orientar o planejamento do professor.

Godino (2011, p 5-6) descreve o processo de estudo como um resultado de seis critérios que ele também vem chamar idoneidades. Vejamos um pouco sobre elas: 1 Epistêmica: grau de representatividade institucional do significado dos objetos matemáticos ${ }^{5}$, a visão de referência da disciplina; 2 - Cognitiva: indica as adequações que devem ser feitas para que os conteúdos, temas, tarefas trabalhadas estejam de acordo com a capacidade de aprendizado dos alunos; 3 - Interacional: observação das interações entre os alunos e destes com o professor, buscando resolver os conflitos de comunicação que se produzem durante a atividade matemática; 4 - Mediacional: grau de disponibilidade e adequação de recursos e tempo; 5 - Emocional (ou Afetiva): grau de envolvimento, interesse e motivação dos alunos com a matemática, os colegas e o professor; 6 - Ecológica: relação entre escola, sociedade e os condicionantes do entorno social, buscando adequar conteúdos ao projeto educativo da escola.

Com base nesses critérios, planejar aulas ou sequências de tarefas, não é um exercício apenas de escolher conteúdos e planificar atividades, mas passa a envolver fatores emocionais (o aluno vai gostar da questão?), epistêmicos (qual o melhor conteúdo, como apresentá-lo?), ecológicos (como contribuir para a inserção social dos aprendizes?), entre outros.

Ainda, diante da complexidade de temas que envolvem trabalhar com os CID, se torna imperativo "destrinchar" cada critério de idoneidade em subitens ou indicadores que possam melhor auxiliar o professor na hora de lidar com eles. Assim, para atingir maior adequação ecológica, por exemplo, deveríamos nos ater, dentre outros, aos seguintes indicadores: 1- a sequência de tarefas busca a relação entre escola e sociedade, respeitando os documentos curriculares da instituição escolar? 2- contempla a busca de valores democráticos e o pensamento crítico? 3 - há relação entre os conteúdos propostos e temas de outras

\footnotetext{
${ }^{5}$ De acordo com Godino Batanero e Font (2008), no EOS objetos matemáticos são quaisquer entidades, coisas, sejam reais ou imaginárias, que participam da atividade matemática. Assim, podemos considerar objetos matemáticos os problemas, objetos geométricos, fórmulas etc.
} 
disciplinas? 4 - as tarefas trazem reflexões sobre o entorno social da escola? (GODINO, 2011, p. 14).

Dentro dessa perspectiva, esse autor nos traz pontuações necessárias sobre todo o complexo de conhecimentos que envolve o trabalho com tarefas e a busca da idoneidade/qualidade didática dos processos de ensino.

\section{Formação de professores e o conhecimento didático-matemático}

A formação de professores de Matemática pode se ancorar a diversas propostas, a exemplo daquelas que utilizam a modelagem matemática (BARBOSA, 2001), as que propõem práticas colaborativas (PONTE; SERRAZINA, 2003), ou ainda, as que discutem o crescimento do conhecimento do professor de Matemática (BALL, 2000; GODINO, 2009; SERRAZINA, 2010, 2012), entre outras. Aqui estamos nos atendo a esta última, buscando aliar as atividades com tarefas ao crescimento do conhecimento didático-matemático do professor, seguindo uma dinâmica semelhante a Godino (2013), Serrazina (2010, 2012) e Soares e Kaiber (2016).

Um ponto comum nas discussões acima é a noção de que, na formação do professor de Matemática, há duas dimensões principais do conhecimento: a primeira é aquela que advém do domínio profundo da matéria que ensina e a segunda que advém do domínio do campo didático, que corresponde a capacidade de criação, implementação e avaliação de situações de aprendizagem, junto à reflexão sobre a prática, que ocorre no processo. Assim, surge um conhecimento didático-matemático, podemos dizer indissociável, fundamental ao professor da área, um misto de estratégias de intervenção, capacidade de comunicação, domínio de conceitos e conteúdos, possibilidades de inovação etc (GODINO, 2009; SERRAZINA, 2010, 2012).

Godino (2009), traça um paralelo entre os CID e as dimensões do conhecimento do professor. Assim, tal conhecimento didático-matemático, é transversado por uma multidimensionalidade, traduzida pelo autor em seis facetas, que coincidem com as idoneidades didáticas: epistêmica, ecológica, cognitiva etc. Dentro do EOS, o processo de busca da adequação didática é, por conseguinte, intimamente ligado aos incrementos no conhecimento do professor.

Por sua vez, o processo formativo que envolve a busca de crescimento do conhecimento tende a desencadear processos de busca de inovação pedagógica, ou seja, aqui 
se entra na dinâmica descrita por Imbernón (2011), por meio da qual não há como o professor se desenvolver em processos formativos sem que isso se reflita, de alguma forma, na qualidade do seu trabalho em sala de aula e na busca de melhorias na sua capacidade de ensinar.

Em direção similar, Serrazina $(2010,2012)$ traz para a mesa a discussão sobre as relações entre formar professores e desenvolver processos de reflexão sobre a prática. Assim, "a formação deve envolver um processo de reflexão questionando as crenças e concepções dos professores envolvidos, de modo a aprofundar o seu conhecimento matemático, didático e curricular", sendo que "o conhecimento profissional do professor, em particular o seu conhecimento didático e matemático, desenvolve-se essencialmente através da reflexão" (SERRAZINA, 2012, p. 272, 273).

\section{(Re)desenho de tarefas}

Enquanto os critérios de idoneidade são os balizadores da atividade matemática na nossa pesquisa, as tarefas, se contextualizadas, são o ponto central da investigação que realizamos. Isso porque, é na tarefa (concepção, planificação, resolução, reflexão), que os contextos são aplicados e, por conseguinte, o conhecimento didático-matemático do professor é posto em movimento.

Dessa forma, estamos aplicando aqui o conceito segundo o qual tarefas são as situações que o professor propõe em classe (exercícios, investigações, problemas), como ponto de partida para a atividade ${ }^{6}$ do aluno, visando a aprendizagem (POCHULU; FONT; RODRIGUEZ, 2013, p. 4999). Esses autores ainda esclarecem que o desenho de tarefas diz respeito ao processo de preparação de situações de aprendizagem, e o redesenho é a contraparte de ajustes e adaptações que ocorre a partir do momento em que os resultados são avaliados pelo professor.

Dessa forma, o processo de (re)desenho de tarefas é importante para o professor, pois pode funcionar como ponto de partida de sua construção de conhecimentos e do desenvolvimento de processos de reflexão, incluindo, além da aplicação em sala de aula, a atividade de propor alterações e reorientações para novas aplicações. Por outro lado, no aluno,

\footnotetext{
${ }^{6}$ Pochulu, Font e Rodriguez, assim como outros autores do campo do desenho de tarefas, ao se referirem à atividade do aluno, estão adentrando no campo da "teoria da atividade" de Vygotsky (1991), onde a atividade é vista como mediação entre o homem e a realidade objetiva. Tais autores, por conseguinte, falam em atividade quando querem atribuir ao aluno um papel ativo diante do conhecimento.
} 
também são desencadeados processos de crescimento, à medida que as reorientações nas tarefas são para estimulá-lo, o que pode incluir mudanças na escrita, utilização de modelos, contextualização, proposição de discussões, revisões, entre outras ações (GODINO, 2013).

Ao tratarmos de tarefas, é preciso levar em conta que elas podem ser de diferentes tipos. Ponte (2005), por exemplo, divide tarefas por duração (curta - exercícios; média problemas e investigações; longa - projetos), por tipo (exercícios, investigações, problemas, exploração), e por contexto (matemática pura, semi-realidade, realidade). Gusmão (2014), por sua vez, nos apresenta dois tipos de tarefas: as fechadas (que apresentam normalmente um tipo de resposta) e as abertas (que permitem, múltiplas respostas, ou múltiplos caminhos para se chegar ao resultado, exigindo alta demanda cognitiva para o aluno). Já Font (2005), trata as tarefas abertas, como situações ricas: aquelas que permitem múltiplas soluções, se inserem em um contexto e permitem discussões e reflexões sobre seus resultados.

\section{Contextos intra e extramatemáticos}

As palavras intra e extramatemática já são quase que autoexplicativas: a primeira exprime as relações dos conteúdos matemáticos entre si, e a outra, as suas relações externas com outras áreas. Mas o que há de mais importante a se saber sobre esses contextos, como eles podem aparecer em tarefas e contribuir para a formação matemática dos alunos?

Há uma relação intrínseca entre contextos e tarefas, afinal, uma situação rica de aprendizagem é um panorama ideal para apresentar uma Matemática capaz de estimular a atividade do aluno ao passo em que proporcione reflexões sobre a realidade social mais ampla. Então, é importante entender que tais situações contextualizadas são o ponto crucial dessa ligação entre o mundo da Matemática e o mundo material/físico. Tais contextos são apresentados por diversos autores (PONTE; QUARESMA, 2012; VANEGAS, 2013; FONT, 2005, 2006;), como intra e extramatemáticos.

A primeira coisa a se desmitificar quando se trata de contextos, ou de contextualização, é que ela não serve apenas como uma "situação diferente", ou uma "ilustração" introdutória de um conceito, como comumente é percebida. Conforme salientam Ponte e Quaresma (2012), a contextualização é uma importante ferramenta de aprendizagem e é uma necessidade em diversas situações de sala de aula.

Assim, o processo de contextualização (utilização de modelos do mundo real para representar objetos matemáticos) não está completo sem uma posterior descontextualização 
(FONT, 2006; PASSOS; SANTOS, 2014), ou seja, o uso de contextos não está correto sem o posterior retorno para o conteúdo, buscando aplicar o mesmo conceito aprendido em outras situações, ou seja, generalizar/globalizar (FONT, 2005, 2006).

$\mathrm{O}$ esquema abaixo nos mostra algumas relações importantes entre os contextos intra e extramatemáticos e destes com a atividade matemática:

Figura 1 - Contextos intra e extramatemáticos.

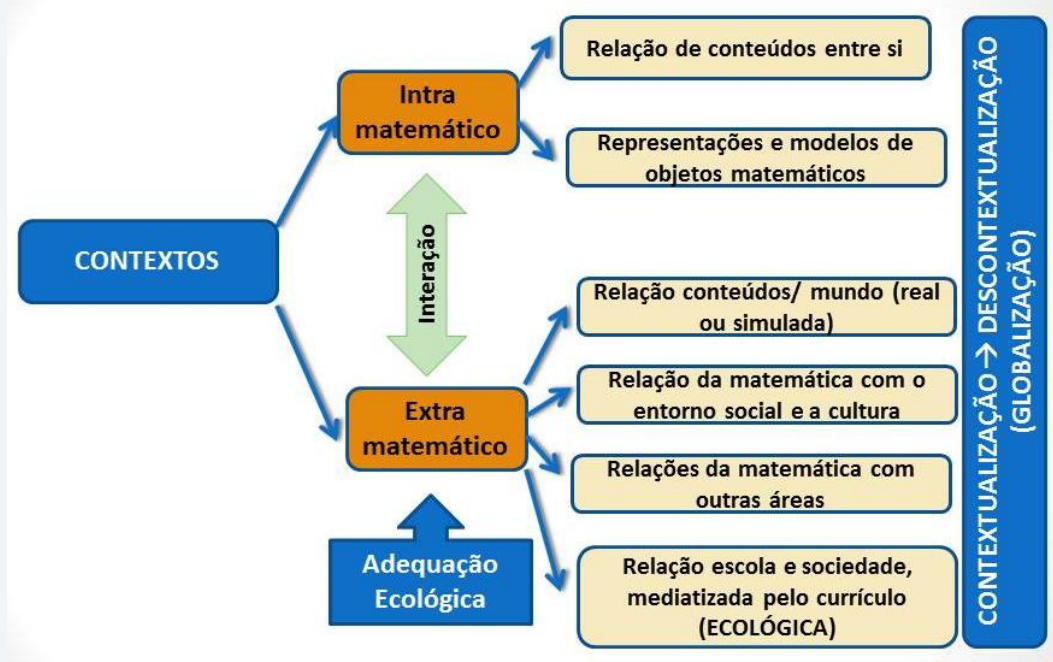

Fonte: elaboração nossa, baseada nas discussões de Ponte e Quaresma (2012) e Font (2006).

A primeira coisa importante a observar sobre a figura acima é que a contextualização pode aparecer em nível intra ou extramatemático, mas há sempre uma interação entre esses dois tipos, uma vez que, nos contextos extramatemáticos também é contemplado o uso de modelos e representações, juntamente com a busca de relações entre conteúdos. A utilização de objetos concretos, figuras, representações etc., pode ser necessária para o entendimento das relações internas/matemáticas entre conteúdos, ou conceitos, ou na compreensão de um ente geométrico etc. Entretanto, em sentido mais amplo, as relações estabelecidas, podem buscar situações do ambiente social (reais ou simuladas), investigações ou experimentações. Neste último caso, já estaremos no campo de relações extramatemáticas, buscando reflexões, discussões, análises da realidade etc. (PONTE; QUARESMA, 2012; SKOVSMOSE, 2008). Em qualquer um dos casos descritos, a volta ao conceito matemático é essencial para produzir aprendizagens.

Dessa forma, a contextualização não se dá apenas relacionando, muitas vezes até de forma forçosa, a matemática com a realidade social mais ampla, e sim em um conjunto de 
processos que envolve, desde as relações de conteúdos matemáticos entre si, passando pelos "problemas situados" (FONT, 2005), ou até mesmo análises mais profundas, envolvendo reflexões sobre a condição de cidadania do aluno (SKOVSMOSE, 2008).

\section{Metodologia}

Este trabalho figura no campo da abordagem qualitativa, na modalidade de PesquisaIntervenção, que pode ser entendida como uma investigação onde as faculdades de produção de conhecimento e de busca de propostas de interferência no contexto de pesquisa não se excluem (CHIZZOTTI, 2006; ROCHA; AGUIAR, 2003). As atividades de intervenção foram realizadas na Escola Vicenzo Gasbarre, na cidade de Jaguaquara, envolvendo três professores, cujos nomes fictícios são Dalva (pedagoga, que leciona em turmas de $6^{\circ}$ ano há 3 anos, mas tem 32 anos em regência de classe), Nilzete (pedagoga e estudante de Licenciatura em Matemática, leciona em turmas do $6^{\circ}$ ao $8^{\circ}$ ano há cerca de 17 anos, com 33 anos de regência) e Samuel (licenciado em Matemática, leciona em turmas do $6^{\circ}$ ao $9^{\circ}$ ano há 17 anos, dos quais, 3 na escola). Juntamente com estes, há o professor pesquisador (codinome PP), que conduz e medeia os encontros formativos.

A intervenção constituiu de duas etapas, onde foram realizados "encontros formativos" com a finalidade de promover ações de planificação, análise e reflexão baseadas em situações ricas de aprendizagem. Em tais encontros, seguimos uma dinâmica similar à de Serrazina (2010), Santos (2015) e Vieira (2015), onde o trabalho com tarefas serviu de desencadeador de ações de formação. A primeira etapa foi composta de discussões no campo do (re)desenho de tarefas e de aprendizado do trato com tais situações de aprendizagem. Na segunda etapa, realizamos o redesenho de sequências de tarefas que compunham um projeto escolar intitulado "O homem do campo", aplicado na escola no ano anterior a pesquisa (2016).

Esta última etapa é a base do artigo aqui apresentado, e teve quatro encontros formativos, com duração entre duas e quatro horas, totalizando 10 horas. No primeiro desses encontros, apresentamos o EOS e as dimensões dos CID; no segundo, fizemos estudos sobre os "indicadores de idoneidade" do CID e iniciamos o (re)desenho da sequência de tarefas "Identificando formas geométricas no campo e na cidade"; no terceiro, fizemos estudos sobre contextos intra e extramatemáticos, e prosseguimos no redesenho das tarefas; e no quarto, 
finalizamos com o (re)desenho da sequência de tarefas "Visita à "feira livre' e ao CEASA", e realizamos uma avaliação final da formação.

Para produzir os dados, recorremos aos seguintes instrumentos: a gravação em áudio dos encontros, as notas de campo (registro das impressões à cada encontro), e os materiais produzidos durante a formação. No tratamento dos dados, utilizamos a análise do tipo categorial, tendo como principais categorias os CID e suas dimensões epistêmica, cognitiva, afetiva, interacional, mediacional e ecológica. Dessa forma, o Enfoque Ontosemiótico, através de suas idoneidades, figura como referencial teórico e metodológico, uma vez que serviu como balizador das situações planificadas, mas também da análise dos resultados obtidos.

Ainda, sobre os CID e as suas categorias, é comum os trabalhos nessa área utilizarem de valorações, ou seja, medirem as idoneidades definindo cada uma como baixa, média ou alta. Juntamente com isso, utilizam de um elemento gráfico (um hexágono, como pode ser visto nas figuras 6 e 7 deste trabalho) para demonstrar visualmente essa valoração.

\section{Análise de dados}

A análise preliminar do projeto "O homem do campo", feita coletivamente pelos professores, marca o início da intervenção/formação com os participantes da pesquisa. Teve como ponto de partida para a discussão uma das tarefas do referido projeto, descrita brevemente nos quadros a seguir:

Quadro 1 - "Identificação de formas geométricas no campo e na cidade".

ATIVIDADE 2 - IDENTIFICANDO FORMAS GEOMÉTRICAS NO CAMPO E
NA CIDADE
-Divisão da sala em dois grandes grupos: Zona Rural (pesquisa no campo) e Zona
urbana (pesquisas na internet - conceitos, construindo paralelos entre os objetos rurais e
urbanos).
ORIENTAÇÕES:
- Observar formas geométricas na paisagem rural. Relatar os locais e as formas
encontradas.
- Buscar relacionar as formas encontradas com conceitos aprendidos anteriormente.
Nomeá-las.
- Descrever formas ainda não conceituadas em sala, para que os professores possam
lhes auxiliar e a conceituá-las em seguida.
- Dar as características geométricas das figuras (faces, arestas, vértices, ângulos etc.)
- Apresentar exemplares ou fotos dos objetos encontrados.

Fonte: Relatório do Projeto “O homem do campo”, Escola Vicenzo Gasbarre, 2016.

O segundo quadro mostra o registro que os professores fizeram das respostas apresentadas pelos alunos às questões lançadas, ao observarem o espaço rural da cidade: 
Quadro 2 - Resultados da implementação da sequência de tarefas "Identificação de formas geométricas no campo e na cidade".

\begin{abstract}
Abaixo um resumo dos itens descobertos e que resultaram nos textos e atividades das próximas tarefas:

Objeto - Parreira de chuchu. Descobertas dos alunos: o trançado do arame, o formato da roça; as gavinhas (relação com amortecedores de motos, conceito de espiral).
\end{abstract}

Objeto - Plantação de tomate Descobertas dos alunos: organização das varas; canteiro de sementes; o formato esférico e oval do tomate.

Objeto: Adubos. Descobertas dos alunos: porções (questões de medidas) e temperatura. Obs: foi realizado um trabalho não profundo sobre medidas de capacidade do meio rural e medidas de temperatura e números inteiros.

Objeto: Rodas de bicicletas. Descobertas dos alunos: formato das rodas; raio das rodas da bicicleta; velocidade da bicicleta em comparação com o ônibus escolar.

Fonte: Relatório do Projeto “O homem do campo”, Escola Vicenzo Gasbarre, 2016.

Partindo da sequência descrita, fizemos uma breve discussão dos resultados do projeto, onde os professores apontaram os avanços e as dificuldades que envolveram as ações desenvolvidas. Registraram que as sequências aplicadas contaram com grande interesse dos alunos, pelo fato de estarem relacionadas ao universo cultural de muitos deles. Ao mesmo tempo, deixaram transparecer que as atividades tiveram um caráter mais informal e aleatório, e não foram o centro das atividades de Matemáticas no período de aplicação.

Para avaliar o projeto escolar em questão e fundamentar o (re)desenho das tarefas nele baseadas, utilizamos uma tabela de valoração com as idoneidades, acompanhadas dos descritores que selecionamos de acordo com a realidade da pesquisa. Este instrumento foi utilizado, inicialmente, para avaliar as sequências de tarefas do projeto "O homem do campo" e, posteriormente, para avaliação do resultado final, com as "novas" tarefas (re)desenhadas:

Quadro 3 - Tabela de valoração das idoneidades utilizada na formação.

\begin{tabular}{|c|c|c|c|c|}
\hline & \multicolumn{3}{|c|}{ VALORAÇÃO DAS IDONEIDADES } \\
\hline & & INDICADORES & $\begin{array}{l}\text { VALORAÇÃO } \\
\text { INICIAL }\end{array}$ & $\begin{array}{l}\text { VALORAÇÃO } \\
\text { FINAL }\end{array}$ \\
\hline 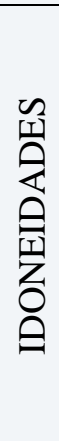 & Epistêmica & $\begin{array}{l}\text { - Conteúdos utilizados são } \\
\text { relevantes e estão de acordo com } \\
\text { os documentos de referência? } \\
\text { - As tarefas são ABERTAS, e } \\
\text { possuem diferentes formas de } \\
\text { expressão matemática (verbal, } \\
\text { gráfica, problemas, cálculos etc)? } \\
\text { - A formalização (planificação: } \\
\text { escrita, } \\
\text { apresentação) da targanização, está }\end{array}$ & MÉDIA & MÉDIA \\
\hline
\end{tabular}




\begin{tabular}{|c|c|c|c|}
\hline & adequada? & & \\
\hline Cognitiva & $\begin{array}{l}\text { - Levou-se em conta os } \\
\text { conhecimentos prévios dos } \\
\text { aprendizes? } \\
\text { - As tarefas estão de acordo com } \\
\text { as capacidades dos aprendizes } \\
\text { (nem fáceis demais nem difíceis } \\
\text { demais), e são desafiadoras na } \\
\text { medida? }\end{array}$ & MÉDIA & $\begin{array}{l}\text { MÉDIA- } \\
\text { MÉDIA }\end{array}$ \\
\hline Mediacional & $\begin{array}{l}\text { - Utilizou-se recursos } \\
\text { diversificados? O tempo foi gerido } \\
\text { adequadamente? }\end{array}$ & BAIXA-ALTA & MÉDIA-ALTA \\
\hline Emocional & $\begin{array}{l}\text { - Tarefas foram criativas, e } \\
\text { ajudaram os aprendizes a } \\
\text { perderem o medo da matemática? } \\
\text { Foi prazeroso realizar as } \\
\text { atividades? }\end{array}$ & MÉDIA-ALTA & MÉDIA-ALTA \\
\hline Interacional & $\begin{array}{l}\text { - Promovem momentos de troca e } \\
\text { interação? } \\
\text { - Houve gestão adequada da } \\
\text { sequência? Resolveu-se conflitos } \\
\text { de significado? Utilizou-se } \\
\text { linguagem clara e adequada? }\end{array}$ & BAIXA-ALTA & $\begin{array}{l}\text { MÉDIA- } \\
\text { MÉDIA }\end{array}$ \\
\hline Ecológica & $\begin{array}{l}\text { - Relacionou-se a Matemática com } \\
\text { outras áreas do saber? } \\
\text { Relacionou-se com a realidade } \\
\text { sociocultural dos aprendizes? }\end{array}$ & MÉDIA-ALTA & ALTA \\
\hline
\end{tabular}

Fonte: Criação nossa, baseada em Godino (2011); Breda, Font e Lima (2015), e Moreira (2017).

A avaliação das idoneidades feita, inicialmente, pelos três professores com alguma intervenção do professor-pesquisador (questionamentos, lembretes, conceitos etc) e, posteriormente, no momento da análise de dados, foi realizada utilizando uma graduação contínua de nove valorações, da menor para a maior, sendo elas: baixa, baixa-baixa, baixamédia, baixa-alta, média, média-baixa, média-media, média-alta e alta. Assim, quando foi atendida uma minoria dos indicadores, valoramos a idoneidade como baixa ou alguma de suas subdivisões (baixa-media, por exemplo), quando atendeu parcialmente esses indicadores, avaliamos como média (ou algum grau mais próximo) e, quando atendeu a maioria, ou todos, a tendência foi avaliar como alta, ou próxima de alta, a idoneidade.

Também foram observadas questões relacionadas com o aprendizado de conceitos e sua aplicação nas tarefas e as reflexões realizadas na formação, pontos que não estão, necessariamente, no quadro dos indicadores (Quadro 3), mas que contribuíram para a valoração realizada.

$\mathrm{Na}$ avaliação inicial, feita pelos professores, as tarefas do projeto "O homem do campo" apresentaram maior grau nas idoneidades ecológica e emocional, pois se revelaram contextualizadas, dentro das expectativas de aprendizagem dos alunos, colocando-os para se 
movimentarem (visitas, investigações etc) e, também se revelaram prazerosas. Por outro lado, os professores relataram alguns conflitos na comunicação e na "gestão de tarefas", juntamente com a pouca quantidade de materiais planificados (a maioria das tarefas foi resolvida na oralidade, de maneira até informal), o que os levou a classificarem como baixa-alta (grau imediatamente inferior à média) as idoneidades mediacional e interacional. Com relação à idoneidade epistêmica, se revelaram divididos pois, ora queriam classificá-la abaixo de média, ora defendiam que sua avaliação como mediana estava correta. De qualquer forma, reconheceram problemas na confecção das tarefas, na utilização de conteúdos baseados nos documentos de referência e na utilização de tarefas abertas. A idoneidade cognitiva, por sua vez, foi definida como mediana.

Partindo para uma análise da sequência de tarefas descrita nos quadros 1 e 2, com base na proposta de (re)desenho de tarefas e nos CID, foi possível perceber que se tratava de uma situação rica, conforme descrita por Font (2005), pois permitia contextualização e globalização de conteúdos, além de estar aberta a várias formulações por parte dos alunos. Por outro lado, a dita sequência também possuía potencial para se adequar a alguns preceitos dados por Pochulu, Font e Rodriguez (2013), como: ser adequada ao nível dos alunos, desafiadora e aberta (pois permitia vários caminhos de resolução).

Assim, percebemos que o conjunto de atividades "Identificando formas geométricas no campo e na cidade" poderia ser (re)desenhado, a fim de enriquecer algumas idoneidades que, inicialmente, estavam com adequação de baixa-alta à média, sendo elas, a epistêmica, a cognitiva, a interacional e a mediacional. Ou seja, no "como" a situação de aprendizagem foi explorada era onde apareciam as lacunas de conhecimento. Primeiro, porque a devolutiva dos professores em relação às descobertas dos alunos se revelou aquém da riqueza da tarefa: leitura e interpretação de textos, exploração pouco profunda de conceitos trazidos pelos alunos (conceito de forma helicoidal, a partir das gavinhas do chuchu, por exemplo), falta de questões planificadas para explorar as descobertas dos estudantes etc. Segundo, porque observamos a predominância da atenção a conceitos (definir as figuras, descrever, dar características), em detrimento da criação de tarefas desafiadoras que os envolvessem.

A partir desse quadro, pensamos uma série de redesenhos que pudessem fortalecer esses pontos vulneráveis detectados e, ao mesmo tempo, provocar reflexões dos professores sobre tarefas e critérios de construção das mesmas. 
Diante do exposto passamos a apresentar algumas situações de aprendizagem retiradas do projeto "O homem do campo", ou criadas pelo professor-pesquisador e, em seguida, o redesenho e suas sucessivas reelaborações por parte dos professores, quando pertinente.

A primeira dessas formulações que levamos para os professores, foi uma tentativa de enriquecer a sequência de tarefas apresentada no Quadro 4, propondo que os professores aprofundassem o entendimento das formas que os alunos encontraram no seu entorno. Assim, apresentamos o seguinte desafio aos professores:

Quadro 4 - Proposta de Redesenho da sequência de tarefas "Identificando formas geométricas no campo e na cidade”.

\section{SEU DESAFIO NESSA TAREFA SERÁ:}

Com base nas orientações dos PCN (ou seja, buscando a adequação epistêmica), escolher um ou mais dos objetos apontados pelos alunos, e preparar com base nele (ou neles) uma ou mais tarefas. Essa tarefa deverá ter as seguintes características:

1 - Apresentar um contexto (intramatemático ou extramatemático) significativo para o aluno, que o auxilie a entender melhor a assunto;

2 - Que seja adequada para esse aluno, portanto, você deverá indicar em qual série e tipo de estudante ela será aplicada (por exemplo, se são estudantes com bom desempenho dentro da série, ou se são estudantes em dificuldades de aprendizado). Lembrando sempre que as tarefas devem ser "na medida", nem fáceis demais, nem dificeis demais, e serem também desafiadoras;

3 - Que procure melhorar a adequação mediacional, ou seja, trazer meios não explorados no projeto aplicado (exploração do ambiente externo, por exemplo, parece não ter sido suficientemente trabalhada nas questões escritas/planificadas) a fim de possibilitar novas possibilidades de exploração da geometria.

Fonte: Acervo da pesquisa

No redesenho, de início, nos chamou à atenção uma tarefa produzida pela professora Dalva, em resposta ao "desafio" acima. Ela apresenta uma construção com várias tarefas juntas e nesse contexto aponta carências na idoneidade epistêmica (dizer por exemplo que as medidas das embalagens são exatas). 
Figura 2 - Redesenho 1: Identificando formas geométricas no campo e na cidade (feito por Dalva)

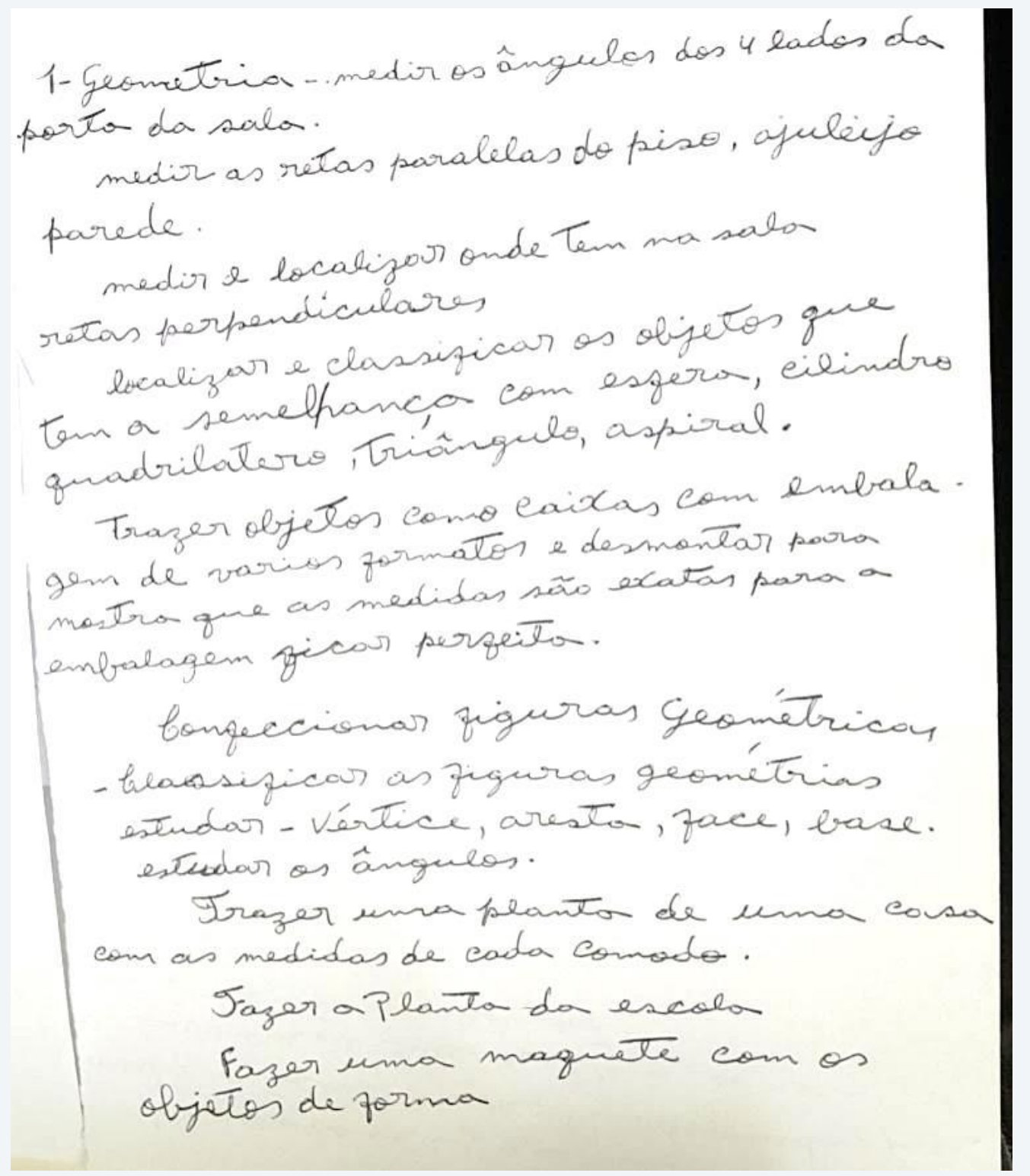

Fonte: Acervo da pesquisa

$\mathrm{Na}$ análise coletiva desta tarefa, foram feitas novas sugestões, e sugerido novo redesenho. Foi observado que a atividade não atendia a alguns critérios pedidos, por exemplo, o de incluir a proposta de situações de modo que, o aluno pudesse fazer registros no papel. Foi então sugerido que a participante diminuísse o tamanho da tarefa, organizasse melhor a situação e incluísse algum cálculo matemático. O resultado dessa interação pode ser visto no quadro 5: 
Quadro 5 - Redesenho 2: Identificando formas geométricas no campo e na cidade (feito por Dalva).

\section{Encontrando formas geométricas na escola:}

- Medir com ajuda de um instrumento matemático, os quatro ângulos da porta da sala;

- Localizar as retas paralelas nos rejuntes do piso e dos azulejos da sala;

- Localizar e classificar, nas dependências da escola, os objetos que tem a semelhança com: esfera; cilindro; quadrilátero; triangulo; espiral;

- Calcule a área e o perímetro da sala de aula; da horta; da quadra poliesportiva.

(O redesenho original da professora apresentava uma foto de internet de alunos medindo uma escola. Por questões de direito autoral a foto foi retirada).

Fonte: Acervo da pesquisa.

Ao observar os redesenhos 1 e 2 nota-se algumas melhoras: aparecem adequações epistêmicas e mediacionais como o uso de instrumentos de medida, a planificação de resultados e o cálculo de áreas. Logicamente, haviam mais questões a serem trabalhadas, como a construção de um roteiro para a tarefa, de forma que orientasse melhor os alunos, a planificação de mais situações etc. Por outro lado, a tarefa em si, principalmente no seu segundo redesenho, representa uma evolução com a tentativa de estabelecer relações entre o ambiente rural e o ambiente escolar, a proposição de uma atividade que pode se revelar prazerosa para os alunos (manipular, medir, registrar descobertas). Assim, Dalva apresentou uma tarefa relacionada ao universo cultural dos alunos, mas que não pode ser considerada totalmente aberta, uma vez que trechos dela, como o "calcule a área e o perímetro da sala", são questões fechadas.

Ainda no projeto da escola, encontramos na sequência de tarefas "Identificando figuras geométricas no campo e na cidade" que os alunos trouxeram para a sala de aula um texto intitulado "O chuchuzeiro", onde eram destacadas características da verdura, como produção, clima propício para plantio, $\mathrm{pH}$ do solo etc. Segundo os professores, a situação foi explorada utilizando discussões e inserindo alguns dos dados do texto em problemas de sala de aula. Foi pedido, então, aos professores que criassem uma tarefa com o tema do texto e buscassem que ela fosse contextualizada e aberta.

Samuel nos apresenta uma tarefa que, segundo ele, é muito significativa para a sua vida, uma vez que é inspirada em sua infância na zona rural, onde seu pai era produtor de chuchu. 
Figura 3 - Redesenho 1: O Chuchuzeiro (feito por Samuel).

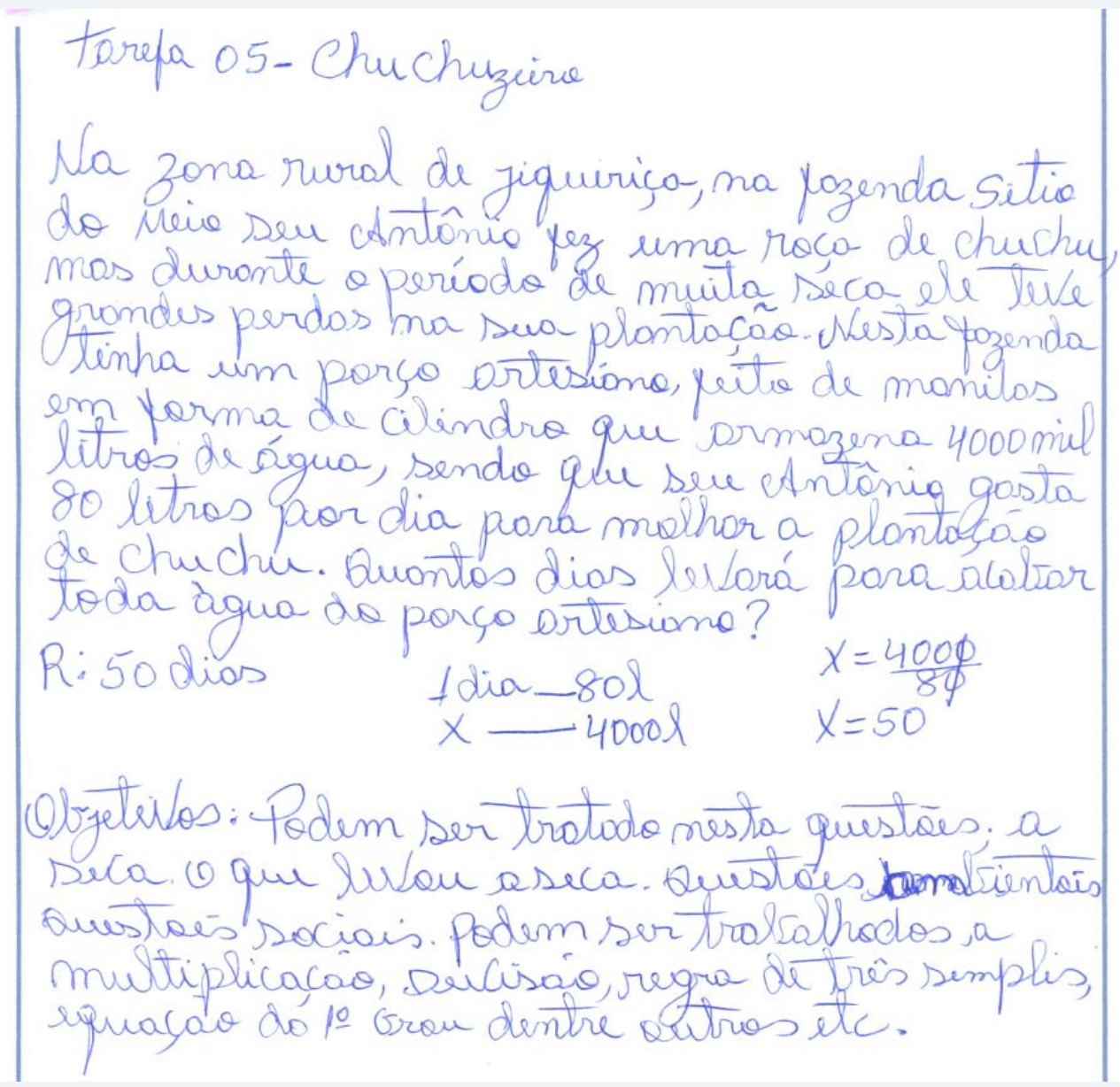

Fonte: Acervo da pesquisa.

Surgiram discussões para que o professor pudesse "abrir a tarefa" e suprimir o assunto "regra de três". Após suprimir a indicação de assunto, o professor contra-argumenta: $a$ abertura vai ser alcançada na resolução, pois o aluno poderá resolver utilizando várias formas... Assim, a questão, depois de "passada a limpo", ficou praticamente com a mesma estrutura. Analisamos que a questão apresenta uma situação contextualizada e pertinente ao que foi sugerido, mas está mais no âmbito das tarefas fechadas do que abertas.

Em outro momento, propomos aos professores o redesenho de outra tarefa aplicada no projeto escolar, intitulada "O tomateiro". Nilzete nos apresenta uma interessante situação inspirada, segundo ela, na tarefa de Sullivan e Clarcke (1992) trabalhada durante a formação e que propunha calcular a área de uma figura, a partir de seu perímetro. No seu redesenho, a professora propõe dispor mudas de tomate em um terreno, com intervalos de $10 \mathrm{em} 10$ metros, em forma de fileiras, tendo como balizador o tamanho desse terreno, de 860 metros. 
Figura 4 - Redesenho 1: “O tomateiro" (feito por Nilzete).

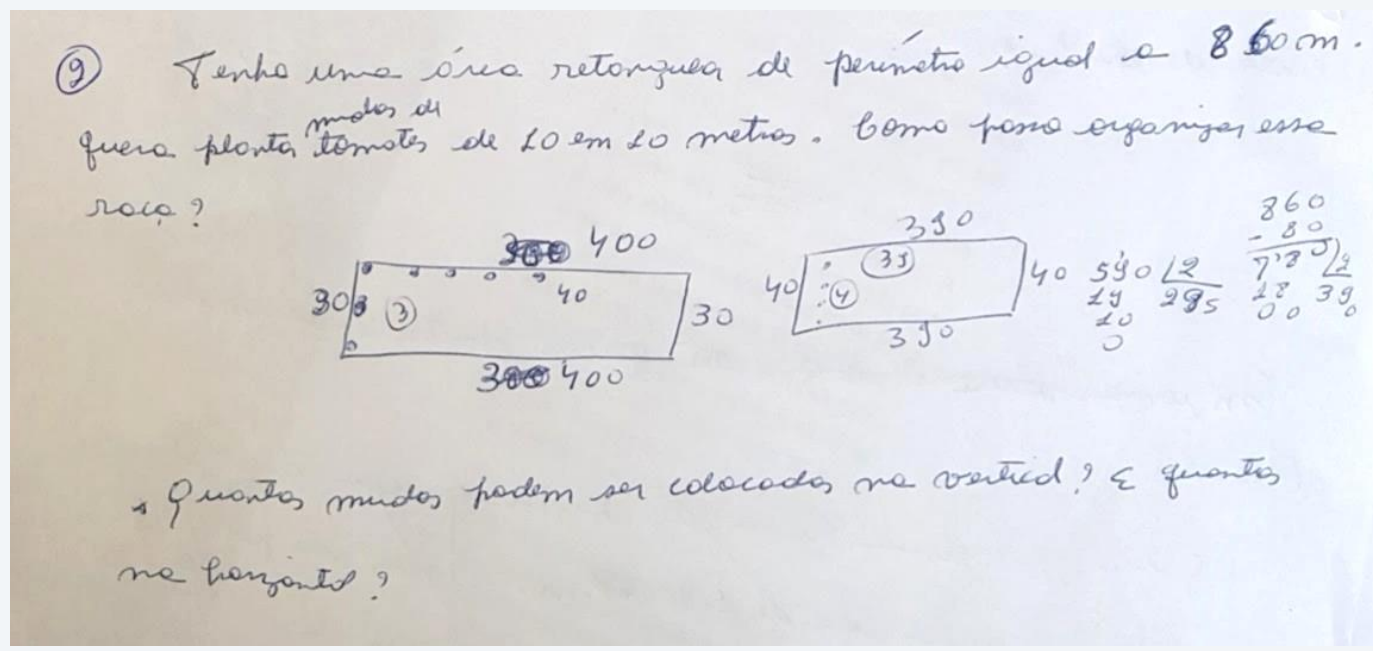

Fonte: Acervo da pesquisa.

Que pese o fato de ser uma proposta contextualizada e que buscava relacionar a uma questão do projeto escolar, a tarefa de Nizete apresenta algumas inconsistências nos campos epistêmico e interacional. Também seu processo comunicativo (escrita da tarefa) pode gerar uma confusão semântica, ao dizer por exemplo perímetro igual, também pareceu forçar a situação ao imaginar mudas de tomate sendo plantadas de 10 em 10 metros. É curioso observar que, ao explicar o que queria na tarefa "fazendo gestos, esquemas, desenhos e falando", a professora obteve mais sucesso que ao expor a planificação no papel.

Apesar das sugestões do grupo de manter a tarefa e fazer as correções necessárias com um redesenho, a professora traz num segundo momento uma tarefa de caráter mais fechado, com direcionamentos, sugestões de procedimentos etc.

Quadro 6-Redesenho 2: "O tomateiro" (feito por Nilzete).

\section{O tomateiro}

Tenho um terreno retangular que será utilizado para plantar mudas de tomate, com as seguintes medidas:

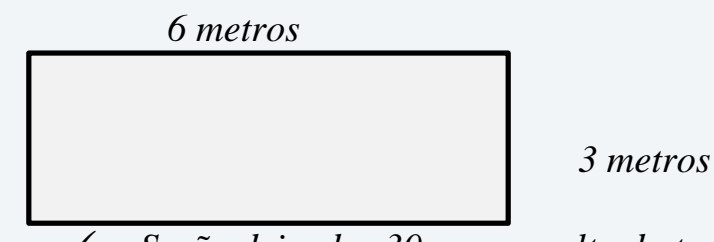

$\checkmark \quad$ Serão deixados $30 \mathrm{~cm}$ em volta do terreno.

$\checkmark$ As mudas serão plantadas com um espaçamento de $30 \mathrm{~cm}$ na horizontal e na vertical.

$\checkmark$ Quantas mudas de tomate serão plantadas nessa área?

(Este redesenho apresentava uma foto de um canteiro de mudas mas, por questões de direito autoral, a foto foi retirada e no lugar foi desenhada a imagem de uma figura retangular similar ao canteiro).

Fonte: Acervo da pesquisa. 
Das três tarefas analisadas, a de Samuel apresenta-se mais interessante, com valor emocional significativo, contextualizada, adequada para alunos de $7^{\circ}$ e $8^{\circ}$ ano do Ensino Fundamental, mas, ainda, de caráter um tanto fechado, sendo que este participante não seguiu a orientação de buscar "abrir a tarefa", pois não achou necessário. Por outro lado, Nilzete e Dalva apresentam tarefas que são melhor entendidas no processo de comunicação oral, mas há problemas de redação textual que elas não conseguiram resolver completamente. No entanto, suas questões rendem boas discussões e com tentativas de abrir o campo de respostas, visando criar várias possibilidades de os alunos tratarem os dados envolvidos.

As três tarefas embora com problemas, seja no domínio da competência escrita, seja em conflitos de significado, não podem nem devem ser medidas por uma régua da máxima valoração, e sim, como parte de um processo. A adequação "deve ser interpretada como relativa às circunstâncias temporais e contextuais instáveis, o que requer uma atitude de reflexão e investigação por parte do professor e demais agentes que compartilham a responsabilidade do projeto educativo" (GODINO; BATANERO; FONT, 2008, p.24).

Levando isso em conta, tendo como base os critérios e indicadores de Godino (2011), podemos inferir que houve avanços em algumas idoneidades e outras se mantiveram estáveis, apresentando crescimento em alguns indicadores e novas dificuldades em outros.

A idoneidade epistêmica, no final do processo apresenta como principal avanço a inserção de "uma mostra mais variada de problemas" (GODINO, 2011) e algumas tarefas abertas. Mas desnuda, por outro lado, uma dificuldade dos professores relacionada a "apresentar definições e procedimentos claros e corretos", um "nível de linguagem adequado" e argumentos (comprovações, explicações) bem fundamentadas (GODINO, 2011, p. 9). Dito de outra forma, quando escrevem, os professores apresentam certos entraves (repetições de palavras, grafia pouco fluente, dificuldades de encontrar termos adequados), que os impedem de tornar suas tarefas mais ricas. Levando todos esses fatores em conta, a nosso ver, essa idoneidade se mantém com valoração média.

Com relação à idoneidade cognitiva, observando os indicadores do quadro 3, podemos considerar que houve melhoras em alguns pontos, como a atenção aos conhecimentos prévios, a busca de propor problemas que sejam desafiadores, adequados etc. Essa idoneidade passa de média para média-média.

As idoneidades mediacional e interacional, avaliadas inicialmente pelos professores como mais problemáticas, apresentaram incrementos em alguns pontos. $\mathrm{O}$ maior problema foi a falta de um recurso crucial, que são as tarefas formalizadas, juntamente com ações de 
registro, manipulação de instrumentos matemáticos etc. Estes obstáculos foram vencidos com o surgimento de uma mostra mais representativa de tarefas, passando a referida idoneidade para média-alta. Já no campo interacional, os conflitos semióticos, que limitam as possibilidades de sucesso de quem resolve tarefas (GODINO, 2002), foram bastante presentes nos encontros iniciais, mas passaram a ser menos frequentes nas atividades finais. Ainda, a atenção aos processos comunicativos (GUERREIRO, 2011) passou a ser mais evidente nos professores ao redesenharem as tarefas, mas não chegou a atingir um avanço significativo, passando então de baixa-alta para média-média.

Por último, as idoneidades ecológica e emocional já tinham boas valorações inicialmente. A emocional, que se manteve ativa nas preocupações dos professores ao elaborarem problemas levando em consideração as necessidades afetivas e socioculturais dos alunos, se mantém como média alta, e a ecológica, passa para alta, uma vez que, apesar do projeto original possuir um teor extramatemático, foi aqui que os participantes passaram a refletir sobre a necessidade da ampliação de conexões intra e extramatemáticas e a busca de diferentes formas de expressão matemática nas suas tarefas contextualizadas.

Neste importante aspecto que diz respeito ao ecológico, ao trabalhar tarefas contextualizadas e discutir os desdobramentos dos temas abordados por elas, as relações matemática/mundo (extramatemáticas) foram se tornando mais evidentes. Ainda assim, é importante salientar o fato de terem sido poucos os momentos em que houve a busca da descontextualização de conteúdos (sair do contexto, e "voltar" para o tratamento matemático da tarefa), no entanto, essa não foi uma falha dos participantes, mas da formação em si, por conta de questões de tempo. Mesmo assim, em alguns momentos das discussões, o tema da descontextualização foi pontuado, mas de forma não aprofundada.

Abaixo, as figuras 5 e 6 resumem a evolução das idoneidades nas atividades de (re)desenho aplicadas:

Figura 5 - Avaliação das idoneidades no início do processo.

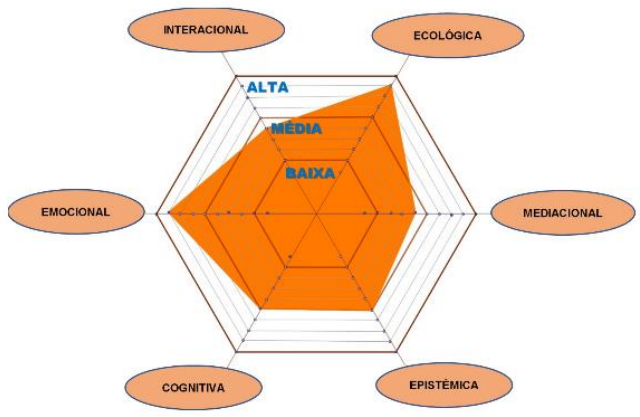

Fonte: produção nossa.
Figura 6 - Avaliação das idoneidades ao final do processo.

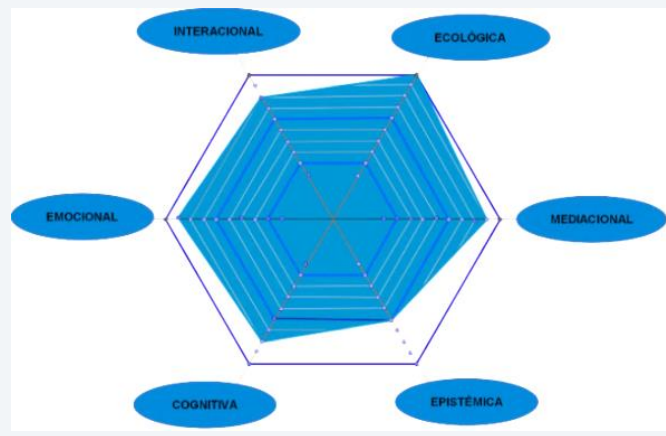

Fonte: produção nossa. 
Comparando as figuras lado a lado, observa-se que: as únicas idoneidades que se mantiveram estáveis foram a epistêmica e a emocional, sendo que esta última já possuía boa valoração anteriormente, mas a epistêmica apresentou avanços ainda tímidos não justificando alteração e mantendo-se média; nas outras idoneidades houve evolução, sendo mais perceptível nos campos mediacional, cognitivo e ecológico; algumas idoneidades tiveram evolução maior que as outras, produzindo um hexágono que ainda se apresenta distante de ser regular, mas que tem aspecto mais amplo (cresceu a valoração na maioria das idoneidades) que o anterior.

Outro ponto importante da formação, além do fato de os professores terem (re)desenhado tarefas, é o processo formativo que circundou essas atividades. A nosso ver, ainda que algumas dificuldades remanesçam com a intervenção, no que toca aos processos de reflexão que a construção de questões desafiadoras desencadeou, os avanços foram bastante significativos. Concordamos com Font (2011, p. 12), quando salienta: "a reflexão sobre a própria prática é necessária para compreender a complexidade do processo educativo" (tradução nossa).

Dessa forma, no processo de desenho e redesenho de tarefas, podemos inferir que houve algo similar ao descrito por Serrazina, onde se buscou "a vivência do processo reflexão-planificação, experimentação, e reflexão, partindo da reflexão sobre os conteúdos a ensinar para a planificação da ação.” (SERRAZINA, 2012, p.276).

Sobre a inserção dos contextos extramatemáticos nas tarefas, observamos alguns avanços que podem ser percebidos nos (re)desenhos mostrados anteriormente: se antes, no projeto "O homem do campo", os professores criaram algumas situações que atuavam em contextos como a área externa da escola ou o entorno rural da cidade, nos (re)desenhos essa capacidade foi potencializada, os contextos foram melhor compreendidos, e uma mostra mais variada de situações e conteúdos foi explorada. Assim, embora os citados problemas no campo epistêmico e interacional pesem é inegável os avanços no domínio de situações que se assemelhem mais a tarefas planificadas que a "exercícios contextualizados".

\section{Conclusões}

Este artigo teve como foco principal identificar relações entre o (re)desenho de tarefas baseadas nos CID e a aproximação da Matemática à outras áreas e ao entorno social da escola. Ao final desse processo, nossa compreensão é de que uma formação baseada no desenho de 
tarefas pode contribuir significativamente, tanto no desenvolvimento do conhecimento dos professores como na sua capacidade de elaborar tarefas contextualizadas e que se relacionem com outros campos, sejam disciplinares, sejam da vida social mais ampla. Assim, as tarefas apresentadas pelos professores, de forma geral, apresentam incrementos nos campos ecológico, emocional, mediacional e cognitivo, mas ainda trazem limitações em alguns aspectos, como os processos comunicativos (na escrita principalmente) e a construção de tarefas abertas com linguagem matemática adequada, ambas relacionadas aos campos interacional e epistêmico.

Quanto ao conhecimento didático-matemático, as falas, as atitudes, as tarefas (re)desenhadas, evidenciam que algo foi "mexido" no modo de trabalho dos professoresparticipantes. De outra forma, se não foi possível sanar todas as lacunas de conhecimento dos professores, houve um significativo incremento em sua base de conhecimento sobre tarefas, sobre o uso de contextos em matemática e, principalmente, sobre as próprias concepções pessoais de ensino e de aprendizagem na área do conhecimento que lecionam.

Por outro lado, ficou perceptível que as dificuldades dos professores, não estavam fundamentadas tanto em questões de cunho ecológico, mas principalmente matemático, e didático. Prova disso é que, entre as tarefas (re)desenhadas encontram-se uma série de objetos do mundo físico, que servem como modelos para o tratamento de dados matemáticos, tais como poços, viveiros, escolas, hortas, "roças", entre outros, em sua maioria, relacionados ao cotidiano do homem do campo ou ao entorno social da escola. Ainda assim, por conta da carência de tempo (sabemos que, em uma formação tão breve, de 7 encontros, fica praticamente impossível resolver todas as lacunas percebidas), a relação contextualização/descontextualização não pôde ser trabalhada com a profundidade necessária, o que revela uma lacuna, não dos participantes, mas da proposta de intervenção em si.

Do ponto de vista das dificuldades deixadas pela pesquisa, as limitações na escrita matemática e no desenvolvimento dos processos comunicativos (escritos e orais) que estão relacionados a ela são as principais lacunas de conhecimento remanescentes. Percebemos que os professores localizam em sua realidade circundante temas e relacionam-os com seus conteúdos de trabalho, mas sentem dificuldades na hora de planificar as tarefas e "colocar as ideias no papel". Ou seja, houve momentos em que os participantes criaram ideias, planificaram tais ideias, mas estas terminaram ficando passíveis de reformulações e orientações futuras para redesenhos. 
Por outro lado, ainda que pesem as intempéries destacadas acima, a nosso ver há ganhos importantes a serem destacados: uma nova concepção de tarefas está lançada e a evolução nessa concepção foi nítida durante a formação. As relações Matemática-mundo foram percebidas, discutidas, e até almejadas, dentro de uma compreensão de que o conteúdo precisa ser aprendido, mas também ressignificado e tornado mais "palatável" aos olhos dos aprendizes.

\section{REFERÊNCIAS}

BALL, D. L. Bridging practices: Intertwining content and pedagogy in teaching and learning to teach. Journal of Teacher Education, 51, 241-247, 2000.

BARBOSA, J. C. Modelagem matemática e os professores: a questão da formação. Bolema, Rio Claro, n. 15, p. 5-23, 2001.

BREDA, Adriana; FONT, Vicenç; LIMA, Valderez. A noção de idoneidade didática e seu uso na formação de professores. IEEM - Jornal Internacional de Estudos em Educação

Matemática 1 - v.8(2)-2015.

CHIZZOTTI, A. Pesquisa qualitativa em ciências humanas e sociais. Petrópolis: Vozes, 2006.

CHRISTIANSEN, B.; WALTHER, G. Tarefa e actividade. In: CHRISTIANSEN, B.; WALTHER, G. Perspectives on mathematics education. Dordrecht: D. Reidel, 1986. p. 243307. Disponível em: 〈http://www.educ.fc.ul.pt/docentes/jponte/sd/mestrado-bibliografia.htm> Acesso em: julho de 2016.

D’AMBRÓSIO, Ubiratan. Educação Matemática: da teoria a prática. São Paulo: Papirus, 1996.

D’AMBRÓSIO, Ubiratan. Educação para uma sociedade em Transição. 2 ed. UDUFRN, 2011.

FERNANDES, Maria Betania Sabino. Funções lineares no ensino médio:

contextualizações e representações. 2014. 181 f. Tese (Doutorado em Educação)

Universidade Federal da Paraíba, João Pessoa, 2014. Disponível em:

http://tede.biblioteca.ufpb.br:8080/handle/tede/8594 Acesso em junho de 2016.

FIORENTINI, D.; LORENZATO, S. Investigação em educação matemática: percursos teóricos e metodológicos. 3. Ed. ver. Campinas, SP: Autores Associados, 2009.

FONT, Vicenç. Competencias profesionales en la formación inicial de profesores de matemáticas de secundaria. Revista Iberoamericana de Educación Matemática - Junho de 2011 - número 26 - 9-25 ISSN: 1815-0640. 
FONT, Vicenç. Problemas em um contexto cotidiano. Universidade de Barcelona. Cuadernos de Pedagogía, 355, 52-54, 2006.

FONT, Vicenç. Reflexión en la clase de Didáctica de las Matemáticas sobre una "situación rica”. In: Badillo, E. Couso, D., Perafrán, G., Adúriz-Bravo, A. (eds) Unidades didácticas en Ciencias y Matemáticas (59-91). Magisterio: Bogotá, 2005.

GODINO, Juan. Categorias de análisis de los conocimientos del profesor de Matemáticas. Revista Iberoamericana de Educación Matemática. Granada. n.20, dez. 2009.

GODINO, Juan. Construyendo un sistema modular e inclusivo de herramientas teóricas para la educación matemática. Actas del Segundo Congreso Internacional Virtual sobre el Enfoque Ontosemiótico, 2017. ISBN: 978-84-617-9047-0

GODINO, Juan. Diseño y análisis de tareas para el desarrollo del conocimiento didácticomatemático de profesores. Actas de las Jornadas Virtuales en Didáctica de la Estadística, Probabilidad y Combinatoria (pp. 1-15). Granada, Departamento de Didáctica de la Matemática de la Universidad de Granada, 2013.

GODINO, Juan. Indicadores de idoneidad didáctica de procesos de enseñanza y aprendizaje de las matemáticas. XIII Conferência Interamericana de Educação Matemática (CIAEM-IACME), Recife (Brasil), 2011.

GODINO, Juan. Un enfoque ontológico y semiótico de la cognición matemática. Recherches en Didactique des Mathématiques, Vol. 22, nº 2.3, pp.237-284, 2002.

GODINO, J., BATANERO, C., FONT, V. Um enfoque onto-semiótico do conhecimento e a instrução matemática. Revista de Ensino de Ciências e Matemática. v. 10, n. 2 - Jul./Dez. 2008.

GODINO, J. D., BENCOMO, D., FONT, V.; WILHELMI, M. R. Análisis y valoración de la idoneidad didáctica de procesos de estudio de las matemáticas. Paradigma, v. XXVII, n. 2, p. 221-252. República Dominicana, 2006.

GUERREIRO, António Manuel da Conceição. Comunicação no ensino aprendizagem da Matemática: práticas no primeiro ciclo do Ensino Básico. Instituto de Educação da Universidade de Lisboa, 2011. Disponível em: http://hdl.handle.net/10451/5494 acesso em agosto de 2017.

GUSMÃO, Tânia Cristina Rocha Silva. Desenho de tarefas para o desenvolvimento da cognição e metacognição matemática. In: I Colóquio Internacional sobre Ensino e didática das Ciências, Feira de Santana, 2014. p.175-180.

GUSMÃO, Tânia Cristina Rocha Silva. Los procesos metacognitivos en la comprensión de las prácticas de los estudiantes cuando resuelven problemas matemáticos: una perspectiva ontosemiótica. Universidade de Santiago de Compostela, 2006.

GUSMÃO, Tânia Cristina Rocha Silva; FERREIRA, Juliana Rodrigues; FAGUNDES, Pedro Souza. Fragilidades do conhecimento matemático e didático do futuro professor dos anos iniciais sobre as operações básicas no sistema de numeração decimal. X Colóquio do Museu Pedagógico, agosto de 2013. ISSN: 2175-5493. 
HERNANDEZ, Fernando e VENTURA, Montserrat. A organização do currículo por projetos de trabalho. Porto Alegre: Artmed, 1998.

IMBERNÓN, Francisco. Formação docente e profissional: formar-se para a mudança e incerteza. 6. ed. São Paulo: Cortez, 2011.

LUDKE, M; ANDRÉ, M. Pesquisa em educação: abordagens qualitativas. Rio de Janeiro: EPU, 1986.

MORAIS FILHO, Daniel Cordeiro de; OLIVEIRA, Michelle Norberta Araújo de. Análise da Contextualização da Função Exponencial e da Função Logarítmica nos Livros Didáticos do Ensino Médio. III Colóquio de Matemática da Região Nordeste, Outubro de 2014. Disponível em: https://www.sbm.org.br/docs/coloquios/NE-3-07.pdf Acesso em julho de 2016.

MOREIRA, Celma Bento. O que Tem Dentro? O que Mudou? Desenho de Tarefas para Promover Percepções Matemáticas na Educação Infantil.

Revista Perspectivas em Educação Matemática Volume 9, número 21, 2016. ISSN 23592842.

MOREIRA, Plínio Cavalcanti, DAVID, Maria Manuela Martins Soares. O conhecimento matemático do professor: formação e prática docente na escola básica. Revista Brasileira de Educação, $\mathrm{n}^{\circ}$ 28, 2005.

PASSOS, Adriana Quimentão; SANTOS Edilaine Regina. Contextualização e descontextualização no processo de matematização: relato de uma experiência. Atas do XII Eprem - Encontro Paranaense de Educação Matemática Campo Mourão, 04 a 06 de setembro de 2014.

PONTE, João Pedro. Gestão curricular em Matemática. In GTI (Ed.), O professor e o desenvolvimento curricular (pp. 11-34). Lisboa: APM, 2005.

PONTE, João Pedro (Org). Práticas Profissionais dos Professores de Matemática. Edição: Instituto de Educação da Universidade de Lisboa. Junho de 2014.

PONTE, João Pedro; QUARESMA, Marisa. O papel do contexto nas tarefas matemáticas. Revista Interações. $N^{\circ}$. 22, pp. 196-216, 2012. Repositório da Universidade de Lisboa. Acesso em Junho de 2017.

PONTE, João Pedro; SERRAZINA, Lurdes. Professores e formadores investigam a sua própria prática: O papel da colaboração. Zetetiké, Vol. 11, No 20, Julho-Agosto 2003.

POCHULU, M; FONT, V. e RODRIGUEZ M. Criterios de diseño de tareas para favorecer el análisis didáctico en la formación de profesores. In: Actas del VII CIBEM. Montevideo: Uruguai. 2013.

POCHULU, Marcel FONT, Vicenç RODRÍGUEZ, Mabel. Desarollo de la competência em análisis didáctico de formadores de futuros professores de Matemática a través del diseño de 
tareas. Revista Latino Americana de Investigación en Matemática Educativa, vol. 19, núm. 1, marzo, 2016, pp. 71-98.

ROCHA, Marisa Lopes da; AGUIAR, Katia Faria de. Pesquisa-Intervenção e a Produção de Novas Análises. Revista Psicologia Ciência e Profissão, 2003, 23.

SACCONI, Luiz Antônio. Dicionário Essencial da Língua Portuguesa. Escala Educacional, 2001.

SANTOS, Silmary Silva. Análise de uma experiência com tarefas matemáticas que exploram a dimensão metacognitiva. PPGECFP-UESB, 2015. Disponível em http://www.uesb.br/ppgecfp/dissertacoes/2013/Silmary-05-05.pdf acesso em 20 de junho de 2016.

SERRAZINA, Maria de Lurdes Marquês. Conhecimento matemático para ensinar: papel da planificação e da reflexão na formação de professores. Revista Eletrônica de Educação. São Carlos, SP: UFSCar, v. 6, no. 1, p.266-283, mai. 2012.

SERRAZINA, Maria de Lurdes Marquês. A Formação Contínua de Professores em Matemática: o conhecimento e a supervisão em sala de aula e a sua influência na alteração das práticas. International Journal for Studies in Mathematics Education, n 2, 2010.

SKOVSMOSE, Ole. Educação matemática crítica: a questão da democracia. 4. ed. Campinas: Papirus, 2008.

SOARES, Maria Elaine dos Santos; KAIBER, Carmem Teresa. Conhecimentos didático matemáticos mobilizados por professores dos anos iniciais: uma análise sob a perspectiva do enfoque ontossemiótico. Acta Scientiae, Canoas - RS. v18 n2 p435-455, mai/ago. 2016. STEIN, M., \& SMITH, M. Tarefas Matemáticas como quadro para a reflexão. Educação e Matemática, 22-28, 2009.

SULliVAN, P. \& CLARKE, D. Problem Solving with Conventional Mathematics Content: Responses of Pupils to Open Mathematical Tasks. Mathematics Education Research Journal, 4(1), 42-60, 1992.

VANEGAS, Yuli. Competencias ciudadanas y desarrollo profesional em matemáticas. Universidade de Barcelona, tese de doutorado, 2013: Biblioteca virtual da Universidade de Barcelona. Disponível em diposit.ub.edu/dspace/bitstream/2445/44766/1/YMVM.TESIS.pdf . Acesso em 25 de maio de 2016.

VANEGAS, Yuli GIMÉNEZ, Joaquim FONT, Vicenç. Aprender a formar em ciudadanía em la formación de professores de matemáticas. Acta Latinoamericana de Matemática Educativa, julho de 2014. Disponível em https://www.researchgate.net/publication/303280234. Acesso em julho de 2016.

VIEIRA, Klyvia Larissa de Andrade Silva. As contribuições formativas de uma sequência didática para atuação dos pedagogos no ensino de Matemática nos anos iniciais. PPGECFP-UESB, 2015. Disponível em http://www2.uesb.br/ppg/ppgecfp/wpcontent/uploads/2017/03/zLarissa_PDF.pdf acesso em 20 de junho de 2016. 
VYGOTSKY, L. S. A formação social da mente. 4. ed. - São Paulo: Martins Fontes, 1991.

ZEICHNER, Kenneth M. A formação reflexiva de professores: Ideias e práticas. Lisboa: EDUCA, 1993.

ZEICHNER, Kenneth M. Uma análise crítica sobre a "reflexão" como conceito estruturante na formação docente. Educação e Sociedade, Campinas, vol. 29, n. 103, p. 535-554, maio/ago. 2008

Nota: Trabalho desenvolvido no marco dos projetos de pesquisa em formação de professores: PGC2018-098603-B-100 (MINECO/FEDER, UE).

\section{$\underline{\text { SOBRE OS AUTORES }}$}

\section{Jorge Ramos de Sousa}

Mestre em Educação Científica e Formação de Professores pela Universidade Estadual do Sudoeste da Bahia (UESB). Integrante do Grupo de Estudos e Pesquisas Museu Pedagógico: Didática das Ciências Experimentais e da Matemática (GDICEM/UESB). Atualmente é professor da Rede Municipal de Ensino da cidade de Jaguaquara-Bahia. E-mail: jrjaguar76@gmail.com

ORCID https://orcid.org/0000-0002-8402-9403

\section{Vicenç Font Moll}

Doctor en Filosofía i ciencias de la educación pela Universitat de Barcelona (UB). Profesor Titular de la Universitat de Barcelona (UB). Facultat d'Educació, Departament d'Educació Lingüística i Literària i de Didàctica de les Ciències Experimentals i de la Matemàtica. Professor Colaborador do Programa Educação Científica e Formação de Professores (PPGECFP) da Universidade Estadual do Sudoeste da Bahia (UESB). E-mail: vfont@ub.edu ORCID https://orcid.org/0000-0003-1405-0458

\section{Tânia Cristina Rocha Silva Gusmão}

Doutora em Didática da Matemática pela Universidade de Santiago de Compostela (USC). Professora na Universidade Estadual do Sudoeste da Bahia (UESB), no Programa de PósGraduação em Educação Científica e Formação de Professores e no Programa de PósGraduação em Ensino, ambos na UESB. Coordenadora do Grupo de Estudos e Pesquisas Museu Pedagógico: Didática das Ciências Experimentais e da Matemática (GDICEM/UESB). E-mail: professorataniagusmao@gmail.com

ORCID https://orcid.org/0000-0001-6253-0435

\section{Nilson Antonio Ferreira Roseira}

Doutor em Educação e Democracia pela Universidade de Barcelona (UB). Professor de Educação Matemática da Universidade Federal do Recôncavo da Bahia (UFRB), Campus de Feira de Santana (BA). É membro do Grupo de Pesquisa em Educação Matemática do Recôncavo da Bahia - GPEMAR, e realiza estudos sobre as relações entre educação matemática, valores e cidadania. E-mail: nroseira.ufrb@gmail.com

ORCID https://orcid.org/ 0000-0001-8777-7944

Recebido em: 22 de abril de 2019 Aprovado em: 10 de maio de 2019 Publicado em: 01 de julho de 2019 